\title{
One-pot high-yield synthesis of Pd nanocubes for Pd-Ir nanocube-based immunoassay of nucleocapsid protein from SARS-CoV-2
}

\author{
Jiuxing $\mathrm{Li}^{1} \cdot$ Yingfu $\mathrm{Li}^{1}$ \\ Received: 1 February 2021 / Revised: 25 February 2021 / Accepted: 2 March 2021 / Published online: 18 March 2021 \\ (C) Springer-Verlag GmbH Germany, part of Springer Nature 2021
}

\begin{abstract}
Pd-Ir nanocubes are promising peroxidase-mimicking nanozymes for immunoassays, enabled by their excellent stability, relatively high catalytic activity, and reproducible performance. A key step involved in the preparation of Pd-Ir nanocubes is the synthesis of Pd nanocubes. However, the traditional method to synthesize Pd nanocubes requires sophisticated and expensive equipment to precisely control the reaction temperature and highly skilled technicians to achieve satisfactory and reproducible product yields. Herein, we report a simple, cost-effective, high-yield (>99\%) and one-pot strategy to synthesize Pd nanocubes with sizes of 7, 18, and $51 \mathrm{~nm}$ for the preparation of Pd-Ir nanocubes. The resulting $18 \mathrm{~nm}$ Pd-Ir nanocubes display three orders of magnitude higher peroxidase activity compared to horseradish peroxidase, leading to a significantly increased detection sensitivity when applied in the immunoassay of nucleocapsid protein from SARS-CoV-2. Due to the simplicity in both material synthesis and assaying procedures and the excellent detection sensitivity, our method should allow for the generalized application of Pd-Ir nanocube-based immunoassays for the diagnosis of human diseases.
\end{abstract}

Keywords One-pot $\cdot$ Pd nanocubes $\cdot$ Pd-Ir nanocubes $\cdot$ Immunoassay $\cdot$ Nucleocapsid protein $\cdot$ SARS-CoV-2

\section{Introduction}

Horseradish peroxidase (HRP) is a protein enzyme capable of specifically converting tetramethylbenzidine (TMB) to colored oxidized products and has been extensively applied in immunoassays through its conjugation with antibodies [1-5]. However, protein enzymes have inherent drawbacks such as susceptibility to denaturation and digestion, the complexity of preparation and purification, and loss of catalytic activity during storage [6, 7]. To address these issues, peroxidase-mimicking nanozymes have been developed [8-10], which include metal oxides $\left(\mathrm{Fe}_{3} \mathrm{O}_{4}\right.$, $\mathrm{V}_{2} \mathrm{O}_{5}, \mathrm{CuO}$, and $\mathrm{Co}_{3} \mathrm{O}_{4}$ ) [11-15], carbon nanomaterials

Published in the topical collection Analytical Chemistry for Infectious Disease Detection and Prevention with guest editors Chaoyong Yang and XiuJun (James) Li.

Yingfu Li

liying@mcmaster.ca

1 Department of Biochemistry and Biomedical Sciences, Michael G. DeGroote Institute of Infectious Disease Research (IIDR), McMaster University, 1280 Main Street West, Hamilton, Ontario L8S 4K1, Canada (graphene oxide and carbon nanotubes) [16, 17], and noble metal nanoparticles (Ag, Au, Pd, Pt, and Ir) [18-20]. Compared to HRP, these peroxidase-mimicking nanozymes display dramatically increased peroxidase activity and are less susceptible to denaturing conditions and protease digestion [8-10]. Moreover, these nanozymes could be easily conjugated with antibodies or aptamers for developing biosensors [21].

Significantly, Pd-Ir nanocubes are one of the most efficient peroxidase-mimicking nanozymes with a catalytic constant $\left(k_{\text {cat }}\right)$ value of $10^{6}-10^{7} \mathrm{~s}^{-1}[7,20]$, which is much higher than metal oxides, carbon nanomaterials, and most noble metal nanoparticles and has enhanced the detection limit of immunoassays by over 2 orders of magnitude [7]. Moreover, Pd-Ir nanocubes display several other attractive features that make them promising nanozymes for immunoassays [7]. First, Pd-Ir nanocubes can be synthesized with high purity and uniformity, ensuring reproducible performance. Second, they can be readily produced with sizes ranging from 8 to $52 \mathrm{~nm}$, allowing fine tuning for specific applications. Third, the synthesis of Pd-Ir nanocubes relies on the deposition of thin Ir layers on Pd nanocubes [7, 20, 22, 23]. Both $\mathrm{Pd}$ and Ir are inert noble metals making them highly stable under strongly basic or acidic conditions. Finally, Pd-Ir nanocubes with varying catalytic activity are readily obtained by adjusting the 
thickness of the Ir shell [23]. However, the traditional method to synthesize Pd nanocubes includes two steps (see Supplementary Information (ESM) Fig. S1) [7, 20, 22, 23], preheating a solution of polyvinyl pyrrolidone (PVP), ascorbic acid (AA), and $\mathrm{KBr}$, followed by the introduction of $\mathrm{Na}_{2} \mathrm{PdCl}_{4}$ solution, which generally leads to compromised yields and reproducibility due to inhomogeneous nucleation. Moreover, this method requires sophisticated and expensive equipment to precisely control the reaction temperature and specialized equipment including glassware, magnetic stirring, and oil baths, which impedes the generalization of Pd nanocube synthesis and application of Pd-Ir nanocube-based immunoassays.

Thus far, coronavirus disease 2019 (COVID-19), a viral infection attributed to severe acute respiratory syndrome coronavirus 2 (SARS-CoV-2), has caused 97,464,094 infections and 2,112,689 deaths globally as of 24 January 2021 according to the World Health Organization [24-26]. To effectively control this pandemic, rapid and accurate diagnosis is of paramount importance. Real-time quantitative polymerase chain reaction (RT-qPCR) and serological virus-induced antibody tests are two major methods for COVID-19 diagnosis due to their merits of high sensitivity or rapid detection, respectively [27-30]. However, there still exist drawbacks for these methods, including false-negative results, time-consuming procedures, and the requirement for certified laboratories for RT-qPCR, and long seroconversion time for antibody tests [28, 31, 32]. Recent reports have suggested that nucleocapsid proteins (NP) are promising candidates for the development of antigen-based immunoassays for COVID-19 diagnosis [33-36].

Here, we report a simple, cost-effective, and one-pot method to synthesize Pd nanocubes at high yields and applied to a highly sensitive Pd-Ir nanocube-based immunoassay for NP from SARS-CoV-2. Several advantages are realized in this method. First, the yield and reproducibility of Pd nanocubes are significantly increased due to homogenous nucleation in a one-pot synthesis. Second, the synthesis process is simplified by avoiding the preheating step, magnetic stirring, and oil bath. Third, disposable polypropylene plastic tubes are used as containers for the synthesis of Pd nanocubes, avoiding heterogeneous nucleation during synthesis as a result of inadequate treatment of glassware with corrosive aqua regia. Also, Pd nanocubes with different sizes can be synthesized by this approach, satisfying the requirements of diverse application platforms. Finally, large-scale synthesis of Pd nanocubes is readily achievable by this approach, making it suitable for commercialization.

\section{Experimental section}

\section{Chemicals and materials}

Sodium tetrachloropalladate(II) $\left(\mathrm{Na}_{2} \mathrm{PdCl}_{4}, 98 \%\right)$, potassium bromide ( $\mathrm{KBr}, \geq 99 \%$ ), polyvinylpyrrolidone (PVP, M.W. $~$
55,000), L-ascorbic acid (AA, $\geq 99 \%$ ), sodium borohydride $\left(\mathrm{NaBH}_{4}, 98 \%\right)$, sodium hexachloroiridate(III) hydrate $\left(\mathrm{Na}_{3} \mathrm{IrCl}_{6} \cdot \mathrm{xH}_{2} \mathrm{O}\right.$, M.W. $\left.=473.9\right)$, acetic acid $($ HOAc, $\geq$ $99.7 \%)$, sodium acetate ( $\mathrm{NaOAc}, \geq 99 \%), 3,3^{\prime}, 5,5^{\prime}$ tetramethylbenzidine (TMB, > 99\%), hydrogen peroxide solution $\left(30 \% \mathrm{w} / \mathrm{v}\right.$ in $\left.\mathrm{H}_{2} \mathrm{O}\right)$, sulfuric acid $\left(\mathrm{H}_{2} \mathrm{SO}_{4}, 95-98 \%\right)$, dimethylformamide (DMF), potassium phosphate monobasic $\left(\mathrm{KH}_{2} \mathrm{PO}_{4}, \geq 99 \%\right)$, sodium phosphate dibasic $\left(\mathrm{Na}_{2} \mathrm{HPO}_{4}, \geq\right.$ $99 \%$ ), potassium chloride ( $\mathrm{KCl}, \geq 99 \%)$, sodium chloride $(\mathrm{NaCl}, \geq 99.5 \%)$, hydrochloric acid $(\mathrm{HCl}, 37 \%)$, bovine serum albumin (BSA, $\geq 98 \%$ ), Tween 20, mPEG-SH (5 kDa), and human prostate-specific antigen (PSA, $\geq 99 \%$ ) were all received from Sigma-Aldrich. Goat anti-mouse IgG, HRP-goat anti-mouse $\operatorname{IgG}$ conjugates, rabbit anti-NP monoclonal antibody $(\mathrm{mAb})$, and mouse anti-NP mAb were obtained from Thermo Fisher Scientific, Inc. Mouse anti-PSA mAb and rabbit anti-PSA polyclonal antibody $(\mathrm{pAb})$ were obtained from Abcam plc. Pooled human saliva was bought from Innovative Research.

\section{Synthesis of Pd nanocubes}

Pd nanocubes were synthesized in a $1.5-\mathrm{mL}$ disposable polypropylene centrifuge tube by a one-pot approach. Briefly, aqueous solution of $\mathrm{Na}_{2} \mathrm{PdCl}_{4}(0.3 \mathrm{~mL}, 64.6 \mathrm{mM}), \mathrm{KBr}$ $(0.5 \mathrm{~mL}, 1 \mathrm{M})$, PVP $(0.2 \mathrm{~mL}, 1 \mathrm{mM})$, and L-ascorbic acid $(0.1 \mathrm{~mL}, 0.4 \mathrm{M})$ were sequentially added to the $1.5-\mathrm{mL}$ centrifuge tube and incubated at $80^{\circ} \mathrm{C}$ for $3 \mathrm{~h}$ to achieve $\mathrm{Pd}$ nanocubes with an edge length of $18 \mathrm{~nm}$. The resulting concentration of Pd nanocubes was calculated to be $44 \mathrm{nM}$. Similarly, Pd nanocubes with an edge length of $7 \mathrm{~nm}$ were synthesized by replacing $\mathrm{KBr}(0.5 \mathrm{~mL}, 1 \mathrm{M})$ with the mixture of $\mathrm{KBr}(0.1 \mathrm{~mL}, 67 \mathrm{mM})$ and $\mathrm{KCl}(0.4 \mathrm{~mL}, 604 \mathrm{mM})$.

To synthesize $51 \mathrm{~nm}$ Pd nanocubes, aqueous solution of $\mathrm{Na}_{2} \mathrm{PdCl}_{4}(0.5 \mathrm{~mL}, 64.6 \mathrm{mM}), \mathrm{KBr}(0.375 \mathrm{~mL}, 1 \mathrm{M}), \mathrm{PVP}$ $(0.286 \mathrm{~mL}, 1 \mathrm{mM})$, L-ascorbic acid $(0.15 \mathrm{~mL}, 0.4 \mathrm{M})$, and $18 \mathrm{~nm}$ Pd nanocubes $(0.045 \mathrm{~mL}, 44 \mathrm{nM})$ and water $(0.389 \mathrm{~mL})$ were sequentially added to a $2-\mathrm{mL}$ centrifuge tube and incubated at $40{ }^{\circ} \mathrm{C}$ for $24 \mathrm{~h}$.

\section{Synthesis of Pd-Ir nanocubes}

Thin Ir layers were deposited on Pd nanocubes to form Pd-Ir nanocubes. In brief, Pd nanocubes $(50 \mu \mathrm{L}, 44 \mathrm{nM}, 18 \mathrm{~nm})$ were centrifuged (18,400 RCF, $10 \mathrm{~min}$ ) to remove the supernatant and twice washed with $1 \mathrm{~mL}$ water followed by centrifugation. Then, Ir deposition was conducted by the addition of an aqueous solution of $\mathrm{Na}_{3} \mathrm{IrCl}_{6}(20 \mu \mathrm{L}, 10 \mathrm{mM})$ and $\mathrm{NaBH}_{4}$ $(20 \mu \mathrm{L}, 100 \mathrm{mM})$, followed incubation at $23{ }^{\circ} \mathrm{C}$ for $1 \mathrm{~h}$. Thereafter, $\mathrm{NaBH}_{4}$ solution $(20 \mu \mathrm{L}, 100 \mathrm{mM})$ was added again and the mixture was reacted at ambient temperature for another $4 \mathrm{~h}$ to attain Pd-Ir nanocubes. The final 
concentration of Pd-Ir nanocubes is identical to the initial Pd nanocube concentration and is calculated to be $2.2 \mathrm{nM}$.

\section{Determination of peroxidase activity of Pd-Ir nanocubes}

Pd-Ir nanocubes $(50 \mu \mathrm{L}, 138 \mathrm{fM})$ and substrate solution $\left(50 \mu \mathrm{L}, 1.6 \mathrm{mM} \mathrm{TMB}, 40 \mathrm{mM}\right.$ acetate buffer, $4 \mathrm{M} \mathrm{H}_{2} \mathrm{O}_{2}$, $\mathrm{pH}$ 4.0) were mixed and incubated in a 96-well microtiter plate at ambient temperature for $20 \mathrm{~min}$. Then, $\mathrm{H}_{2} \mathrm{SO}_{4}$ $(20 \mu \mathrm{L}, 2 \mathrm{M})$ was added to terminate the reaction. The absorbance of oxidized TMB at $450 \mathrm{~nm}$ was measured by a microplate reader to compare the peroxidase activity of Pd-Ir nanocubes.

\section{Steady-state kinetic assay}

The steady-state kinetic assay was performed by monitoring the catalytic oxidation of TMB with $\mathrm{H}_{2} \mathrm{O}_{2}$. Briefly, Pd-Ir nanocubes $\left(50 \mu \mathrm{L}, 2.76 \times 10^{-13} \mathrm{M}\right)$ and $\mathrm{H}_{2} \mathrm{O}_{2}(50 \mu \mathrm{L}, 8 \mathrm{M})$ were added to a cuvette with a $1-\mathrm{cm}$ path length. Then, TMB substrate $(100 \mu \mathrm{L}, 1.6 \mathrm{mM} \mathrm{TMB}, 40 \mathrm{mM}$ acetate buffer, $\mathrm{pH} 4.0$ ) was introduced to initiate the catalytic reaction, during which TMB was oxidized to generate a blue product with a specific absorption peak at $653 \mathrm{~nm}$. UV-Vis absorption spectroscopy was employed to monitor the absorbance for $300 \mathrm{~s}$ at intervals of $12 \mathrm{~s}$. The concentrations of TMB and $\mathrm{H}_{2} \mathrm{O}_{2}$ were adjusted independently to establish the initial reaction velocity $(v)$ at a given substrate concentration. $v$ is determined by the initial slope of kinetic curves using the extinction coefficient of $3.9 \times 10^{-4} \mathrm{M}^{-1} \mathrm{~cm}^{-1}$ for oxidized TMB at $653 \mathrm{~nm}$. Michaelis-Menten equation, $v=V_{\max } \times[S] /\left(K_{\mathrm{m}}+[S]\right)$, is used to calculate the apparent kinetic parameters, where $v$ refers to the initial reaction velocity, $V_{\max }$ stands for the maximal reaction velocity, $[S]$ means the concentration of substrate, and $K_{\mathrm{m}}$ is the Michaelis constant.

\section{Preparation of Pd-Ir nanocube-antibody complex}

Goat anti-mouse $\operatorname{IgG}$ is conjugated with Pd-Ir nanocubes through physical adsorption along with mPEG-SH $(5 \mathrm{kDa})$. In brief, goat anti-mouse $\operatorname{IgG}(5 \mu \mathrm{L}, 1 \mathrm{mg} / \mathrm{mL})$ was mixed with mPEG-SH $(10 \mu \mathrm{L}, 100 \mu \mathrm{M})$ in a $1.5-\mathrm{mL}$ centrifuge tube, followed by the addition of Pd-Ir nanocubes ( $1 \mathrm{~mL}, 0.55 \mathrm{nM})$. After incubation at ambient temperature for $1 \mathrm{~h}$, BSA $(200 \mu \mathrm{L}, 10 \% \mathrm{w} / \mathrm{v})$ was added to block Pd-Ir nanocubes. The reaction proceeded at ambient temperature for $1 \mathrm{~h}$, and the complex was obtained after washing and centrifuging $(10,000 \mathrm{rpm}, 5 \mathrm{~min})$ twice with BSA solution $(1 \mathrm{~mL}, 1 \%$ $\mathrm{w} / \mathrm{v})$. Finally, storage buffer $\left(1 \mathrm{~mL}, 1.8 \mathrm{mM} \mathrm{KH}_{2} \mathrm{PO}_{4}\right.$, $10 \mathrm{mM} \mathrm{Na}_{2} \mathrm{HPO}_{4}, 2.7 \mathrm{mM} \mathrm{KCl}, 137 \mathrm{mM} \mathrm{NaCl}, 10 \% \mathrm{w} / \mathrm{v}$ BSA, $0.05 \% \mathrm{v} / \mathrm{v}$ Tween-20) was used to disperse the complex, which was stored at $4{ }^{\circ} \mathrm{C}$ for $12 \mathrm{~h}$ before use.

\section{Immunoassay by Pd-Ir nanocubes}

Immunoassays were carried out in the wells of a microtiter plate. After the introduction of each reagent, the wells were washed three times by PBST $(200 \mu \mathrm{L}$, PBS, $0.05 \%$ $\mathrm{v} / \mathrm{v}$ Tween-20). First, rabbit anti-NP mAb $(100 \mu \mathrm{L}, 5 \mu \mathrm{g} /$ $\mathrm{mL}$ ) in PBS was added to the wells of a microtiter plate and incubated at $4{ }^{\circ} \mathrm{C}$ for $12 \mathrm{~h}$. Then, a blocking buffer (200 $\mu \mathrm{L}$, PBST, $2 \% \mathrm{w} / \mathrm{v}$ BSA) was used to block the wells by incubation at $37{ }^{\circ} \mathrm{C}$ for $1 \mathrm{~h}$. Afterward, NP samples dispersed in dilution buffer $(100 \mu \mathrm{L}$, PBST, $0.1 \% \mathrm{w} /$ v BSA) were introduced and shaken at $100 \mathrm{rpm}$ at $25^{\circ} \mathrm{C}$ for $2 \mathrm{~h}$. Next, mouse anti-NP mAb $(100 \mu \mathrm{L}, 2 \mu \mathrm{g} / \mathrm{mL})$ in dilution buffer was added to bind with NP shaking at $100 \mathrm{rpm}$ at $25{ }^{\circ} \mathrm{C}$ for $1 \mathrm{~h}$. Finally, Pd-Ir nanocubes $(100 \mu \mathrm{L}, 0.138 \mathrm{nM})$ conjugated with goat anti-mouse $\mathrm{IgG}$ were introduced, followed by shaking at $100 \mathrm{rpm}$ and $25{ }^{\circ} \mathrm{C}$ for $1 \mathrm{~h}$. TMB substrate $\left(100 \mu \mathrm{L}, 2 \mathrm{M} \mathrm{H}_{2} \mathrm{O}_{2}\right.$, $0.8 \mathrm{mM}$ TMB, $20 \mathrm{mM}$ acetate buffer, $\mathrm{pH} 4.0$ ) was then introduced and incubated at $25{ }^{\circ} \mathrm{C}$ for $20 \mathrm{~min}$. The catalytic reaction was terminated by the addition of $\mathrm{H}_{2} \mathrm{SO}_{4}$ $(20 \mu \mathrm{L}, 2 \mathrm{M})$. A microplate reader was utilized to measure the UV-Vis absorbance at $450 \mathrm{~nm}$ to determine NP concentration by comparing it with a standard curve.

For comparison, an HRP-based immunoassay was also carried out for the detection of NP. Similarly, rabbit anti$\mathrm{NP} \mathrm{mAb}, \mathrm{NP}$, and mouse anti-NP mAb were bound to the wells of the microtiter plate as described above. Then, HRP-goat anti-mouse IgG conjugates $(100 \mu \mathrm{L}, 0.5 \mu \mathrm{g} /$ $\mathrm{mL}$ ) in dilution buffer was added, followed by shaking at $100 \mathrm{rpm}$ and $25{ }^{\circ} \mathrm{C}$ for $1 \mathrm{~h}$. Finally, TMB substrate $\left(100 \mu \mathrm{L}, 10 \mathrm{mM} \mathrm{H} \mathrm{O}_{2}, 0.8 \mathrm{mM} \mathrm{TMB}, 20 \mathrm{mM}\right.$ acetate buffer, $\mathrm{pH} 4.0$ ) was added and incubated at $25{ }^{\circ} \mathrm{C}$ for $20 \mathrm{~min}$. The UV-Vis absorbance at $450 \mathrm{~nm}$ was measured by a microplate reader to determine NP concentration. Similarly, immunoassays for PSA were performed as described above except the use of antibodies specific for PSA.

\section{Characterizations}

UV-Vis absorbance was measured with a Tecan microplate reader or monitored by an Agilent Cary $60 \mathrm{UV}$-Vis absorption spectrometer. SEM and EDX analyses were carried out on a Hitachi S-4700 FE-SEM at $20 \mathrm{kV}$. TEM analyses were performed with a JEOL JEM-2010 TEM at $200 \mathrm{kV}$. HR-TEM analyses were carried out on an FEI Titan 80-300 LB TEM at $300 \mathrm{kV}$. HAADF-STEM analyses and EDX mapping were performed on an FEI Titan 80-300 HB Cubed microscope at $200 \mathrm{kV}$. An Oakton $\mathrm{pH}$ meter was used to measure the $\mathrm{pH}$ of different buffer solutions. 


\section{Results and discussion}

\section{Working principle of the synthesis of Pd and Pd-Ir nanocubes for immunoassays}

As depicted in Fig. 1, Pd nanocubes are synthesized in a disposable tube by sequential addition of metal precursors $\left(\mathrm{Na}_{2} \mathrm{PdCl}_{4}\right)$, capping agent $(\mathrm{KBr})$, surfactant (polyvinyl pyrrolidone, $\mathrm{PVP}$ ), and reducing agent (L-ascorbic acid, AA). After reaction at $80{ }^{\circ} \mathrm{C}$ for $3 \mathrm{~h}, \mathrm{Pd}$ nanocubes are obtained with a yield of higher than $99 \%$. Pd nanocubes are washed twice by centrifugation and resuspension in water. To achieve Pd-Ir nanocubes with outstanding peroxidase activity, thin Ir layers are evenly deposited on the surface of Pd nanocubes. As most surfactants are removed during the wash steps before the deposition of Ir shells, the secondary antibody can be efficiently coupled to Pd-Ir nanocubes through physical adsorption. The resulting antibody-nanocube complexes display both recognition ability and peroxidase activity and are exploited for immunoassays of NP from SARS-CoV-2. Capture antibodies are coated on the wells of a microtiter plate by physical adsorption. In the presence of the target, the secondary antibody-nanocube complexes are captured on the substrate through the binding with detection antibody, catalyzing the oxidation of TMB with $\mathrm{H}_{2} \mathrm{O}_{2}$ to generate colored oxidized products. The concentration of the targets is determined by comparing the absorbance of oxidized products with a standard curve.

\section{Characterization of Pd and Pd-Ir nanocubes}

To ensure accurate and reproducible testing performance, Pd-Ir nanocubes must be prepared with high yields and well-defined structure. Pd nanocubes were synthesized using the one-pot approach as described above, followed by extensive washes to remove capping agents. The sizes and morphologies of nanomaterials were characterized by scanning electron microscopy (SEM) and transmission electron microscopy (TEM). As shown in Fig. 2, a and b, and S2, a and b, well-defined cubic Pd nanoparticles are obtained with a yield greater than $99 \%$, revealing an edge length of $18.2 \pm 2.0 \mathrm{~nm}$ through statistical analysis (Fig. 2c). The high yield of Pd nanocubes is attributed to the homogenous nucleation of seed particles during one-pot synthesis. After coating with thin Ir layers, Pd-Ir holds the cubic shape without significant variation in particle size and morphology (Fig. 2d and S2c). The presence of Ir shells is further confirmed by energy dispersive X-ray analyses (EDX) (ESM Fig. S2, $d$ and e), which exhibits apparent Ir peaks for Pd-Ir nanocubes in comparison with Pd nanocubes. Moreover, the crystal structure of Pd-Ir nanocubes was characterized by high-resolution TEM (HR-TEM, Fig. 2e), which reveals the typical lattice distance of $0.191 \mathrm{~nm}$ for Pd nanocubes and the epitaxial relationship between Pd and Ir together with the Fourier transform pattern (ESM Fig. S2f). Finally, high-angle annular dark-field scanning transmission electron microscopy (HAADF-STEM) and EDX mapping are employed to characterize the thickness and distribution of Ir shells. As shown in ESM Fig. S2g, thin Ir shells can be resolved by a close examination of the low-magnification HAADF-STEM image for the brighter area. The thickness and distribution of Ir shells are examined by high-magnification HAADF-STEM analysis of a single Pd-Ir nanocube (Fig. 2f) along with corresponding EDX mapping (ESM Fig. S2h), presenting the uniform distribution of Ir around the Pd nanocube with a shell thickness of about $1 \mathrm{~nm}$. Taken together, this one-pot synthesis approach can be utilized to prepare Pd-Ir nanocubes with high yield and well-defined structures.
Fig. 1 Schematic illustration of synthesis, functionalization, and application of Pd-Ir nanocubes for immunoassays

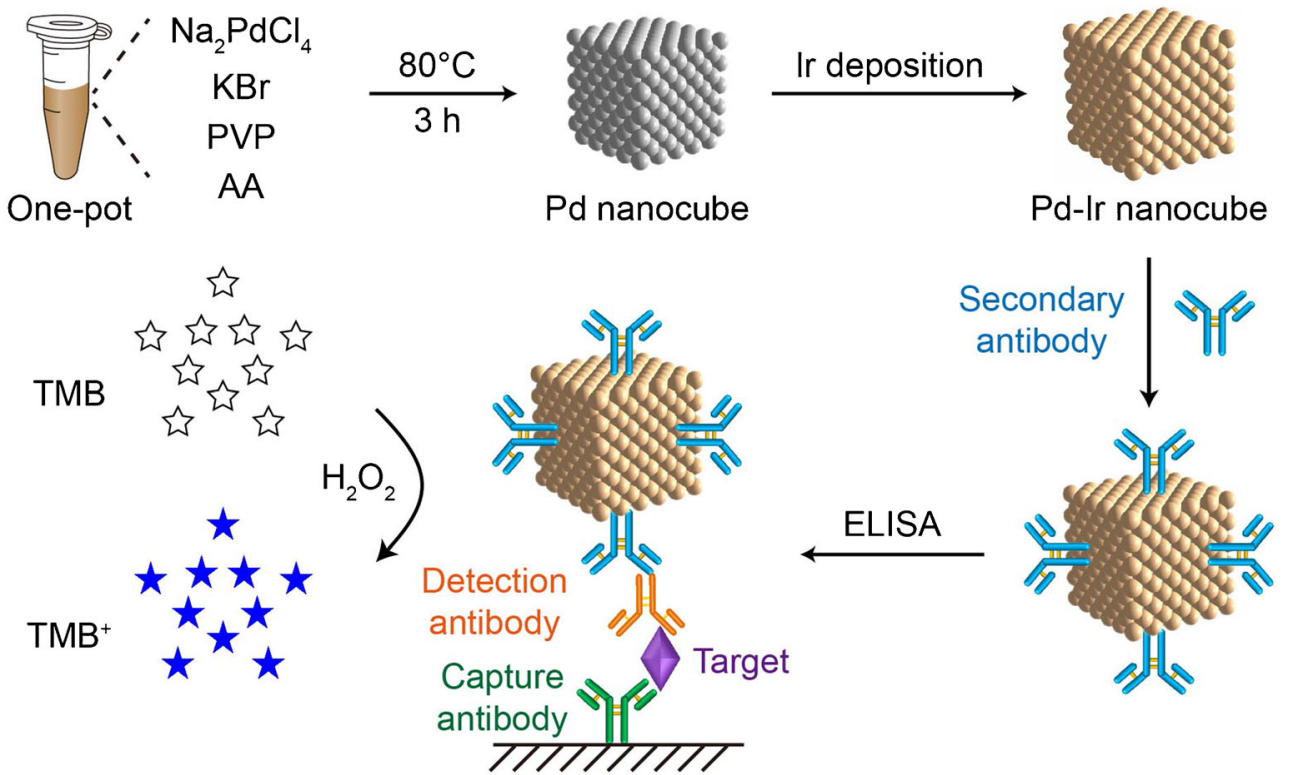




\section{Optimization of synthesis conditions for Pd nanocubes}

To demonstrate the advantages of our one-pot approach for the synthesis of Pd nanocubes over the traditional method, the yield of Pd nanocubes from three batches synthesized by both methods were compared. As shown in ESM Figs. S3 and S4, the one-pot method displays a significantly higher yield of Pd nanocubes than the traditional method, revealing good consistency and reproducibility of the one-pot synthesis approach for the preparation of Pd-Ir nanocubes. Subsequently, the influence of reagent concentration on the yield of Pd nanocubes was examined by lowering the concentration of each component individually. As shown in Fig. 3 and ESM Figs. S5, S6, and $\mathrm{S} 7$, an obvious decreasing yield of Pd nanocubes was observed with decreasing concentrations of $\mathrm{Na}_{2} \mathrm{PdCl}_{4}$, Lascorbic acid, $\mathrm{KBr}$, or PVP, accompanied by the appearance of other morphologies of Pd nanoparticles. First, Pd nanorods and irregular Pd nanoparticles (Fig. 3) were formed at decreased concentrations of $\mathrm{Na}_{2} \mathrm{PdCl}_{4}$ (metal precursor) and L-ascorbic acid (reducing agent), due largely to lowered reaction kinetics. Second, Pd nanocubes were transformed into spherical Pd nanoparticles with the reduction of $\mathrm{KBr}$ concentration (ESM Fig. S6a), which is responsible for capping the $\{100\}$ crystal faces of Pd nanomaterials [37]. Furthermore, large Pd particles were observed with lowered PVP concentrations (ESM Fig. S6b) possibly as a result of the aggregation of Pd seeds during particle growth. Finally, this strategy is explored for the synthesis of varying sizes of Pd nanocubes. As shown in Fig. 4, Pd nanocubes with edge lengths of $50.7 \pm$ $5.1 \mathrm{~nm}$ and $7.4 \pm 1.5 \mathrm{~nm}$ are produced with high yields, demonstrating the versatility of this synthesis method.

\section{Catalytic kinetic assay of Pd-Ir nanocubes}

The inherent peroxidase activity of Ir can be further enhanced by Pd through the electronic effect between two metals [7]. Here, the peroxidase activity of Pd-Ir
Fig. 2 a SEM, b TEM, and c size distribution analysis of $\mathrm{Pd}$ nanocubes. d TEM, e HR-TEM, and $\mathbf{f}$ HAADF-STEM image and EDX mapping images of Pd-Ir nanocubes

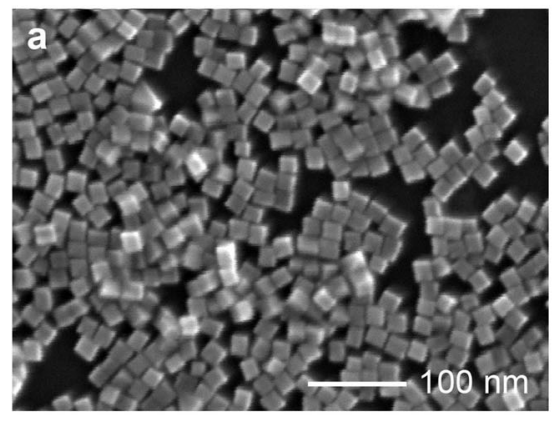

C
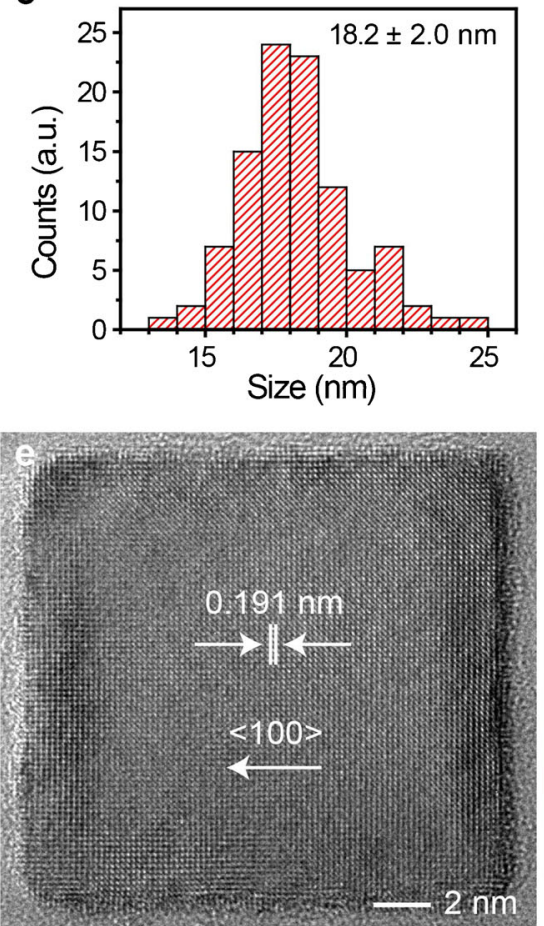

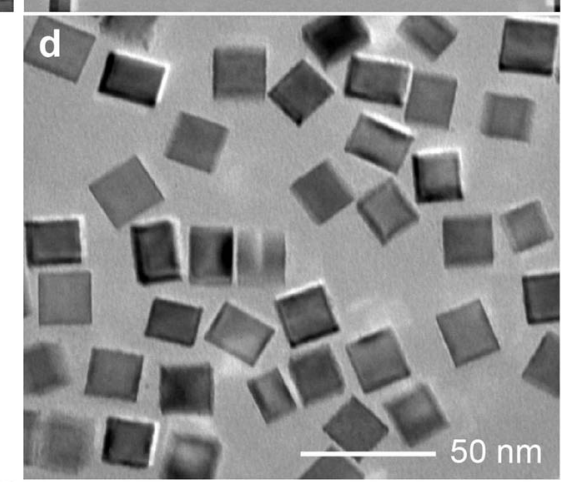

f
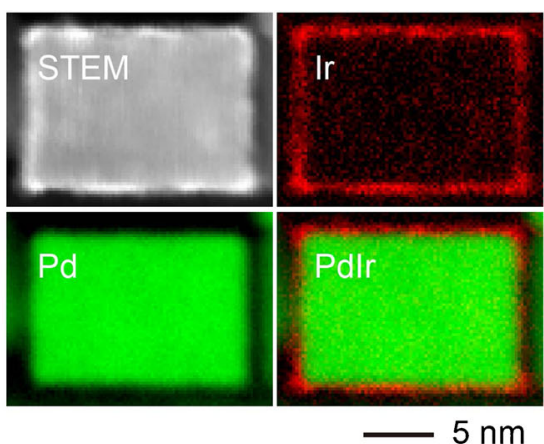
Fig. 3 Synthesis of Pd nanocubes with decreased concentrations of a $\mathrm{Na}_{2} \mathrm{PdCl}_{4}$ and $\mathbf{b}$ L-ascorbic acid. Default conditions: $17.6 \mathrm{mM}$ $\mathrm{Na}_{2} \mathrm{PdCl}_{4}, 36.4 \mathrm{mM}$ L-ascorbic acid, $454 \mathrm{mM} \mathrm{KBr}$, and $0.182 \mathrm{mM}$ PVP
Fig. 4 TEM analyses of a $51 \mathrm{~nm}$ and $\mathbf{b} 7 \mathrm{~nm}$ Pd nanocubes. Statistical size distribution analyses of $\mathbf{c} 51 \mathrm{~nm}$ and $\mathbf{d} 7 \mathrm{~nm}$ Pd nanocubes
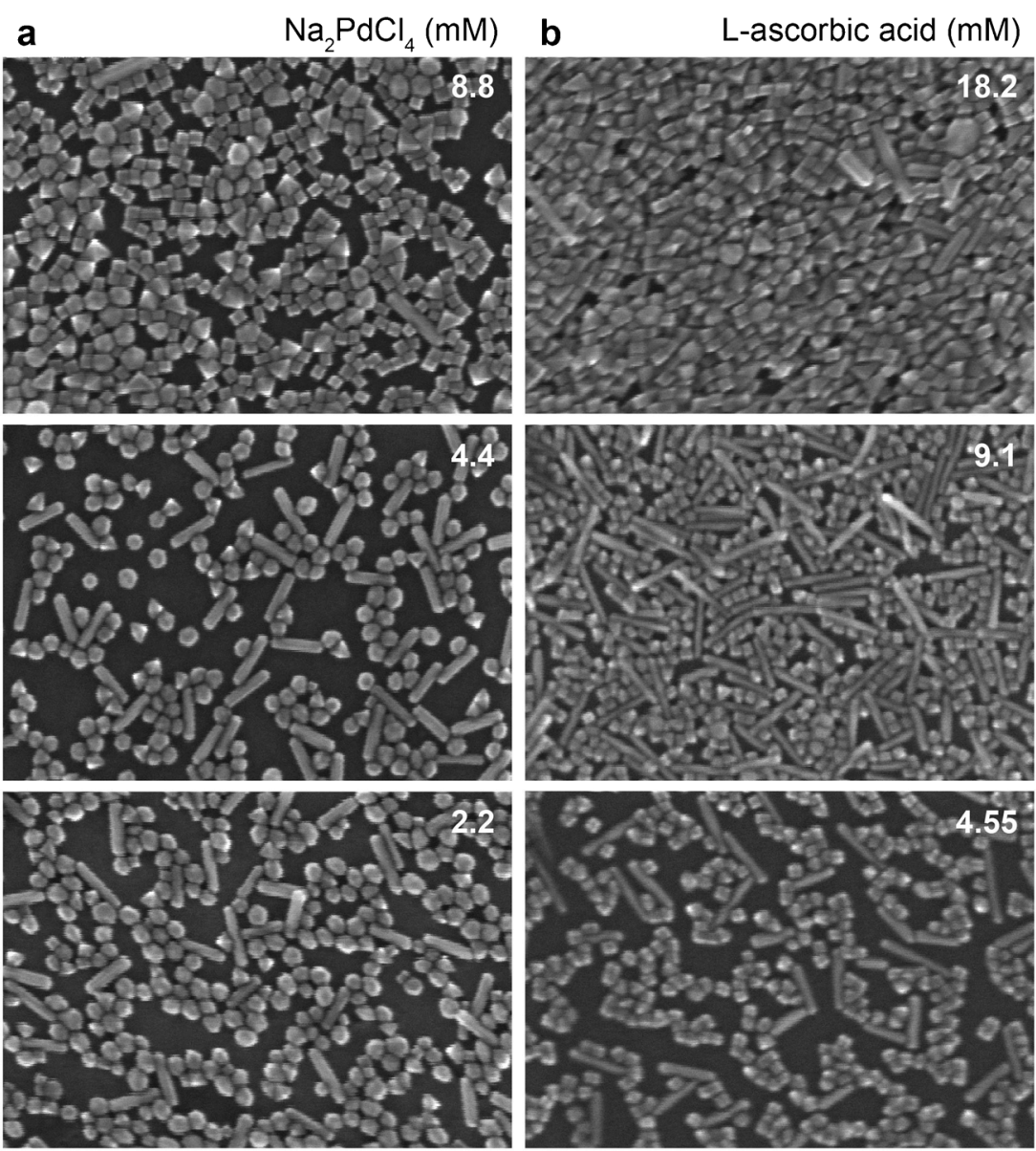

$-100 \mathrm{~nm}$
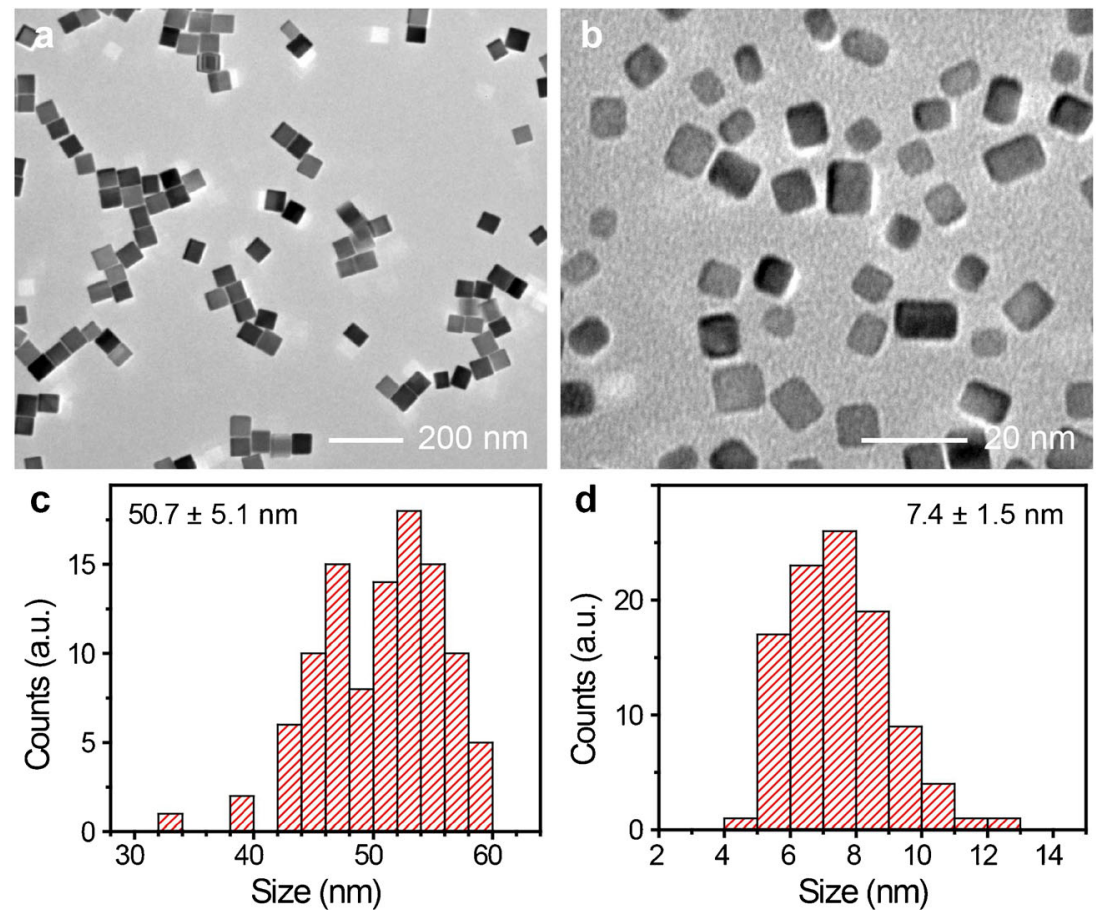
Fig. 5 Plots of initial reaction velocities versus $\mathbf{a}$ TMB and $\mathbf{b}$ $\mathrm{H}_{2} \mathrm{O}_{2}$ concentrations. Double reciprocal plots of initial reaction velocities against $\mathbf{c}$ TMB and $\mathbf{d}$ $\mathrm{H}_{2} \mathrm{O}_{2}$ concentrations
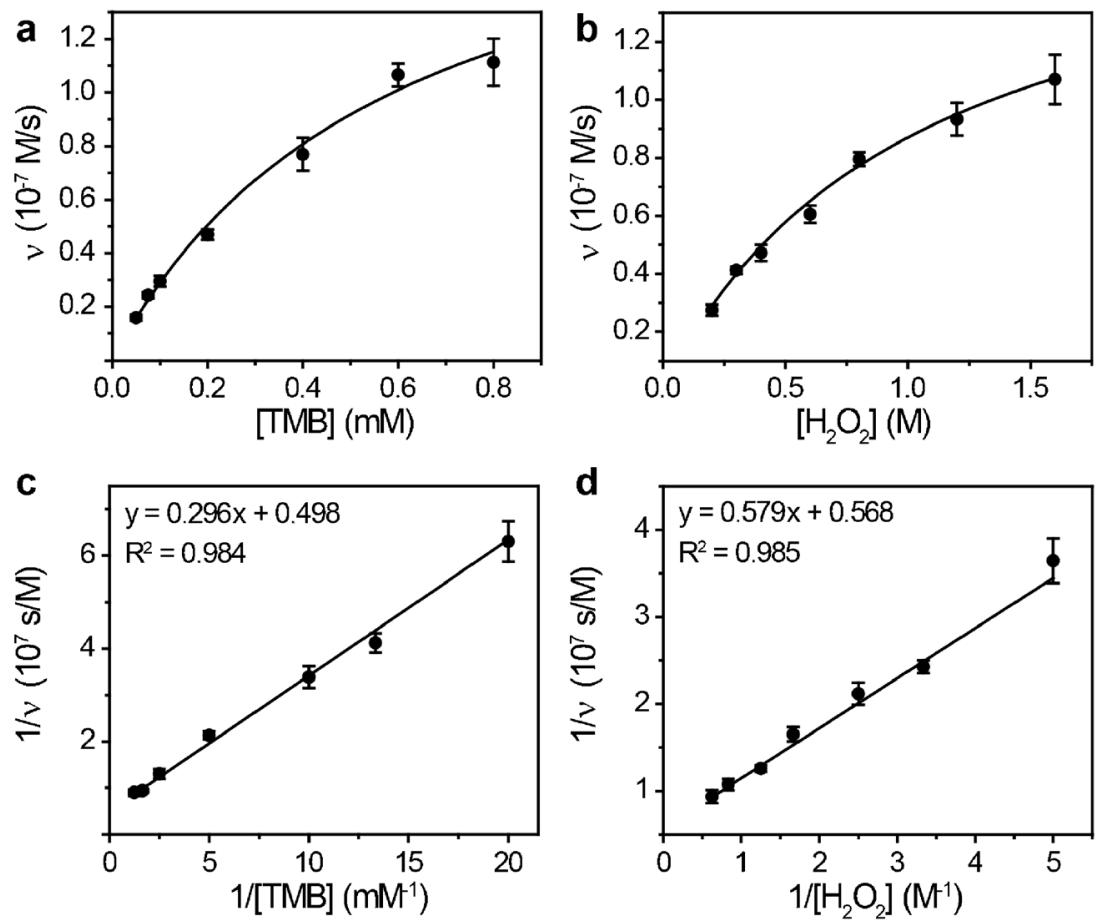

nanocubes was demonstrated by catalyzing the oxidation of TMB with $\mathrm{H}_{2} \mathrm{O}_{2}$. Pd-Ir nanocubes were mixed with TMB and $\mathrm{H}_{2} \mathrm{O}_{2}$ in a cuvette in $\mathrm{pH} 4$ buffer solution. Then, the absorbance of oxidized TMB at $450 \mathrm{~nm}$ was monitored in real time for $20 \mathrm{~min}$ to achieve the catalytic kinetic curves. The initial reaction velocity $(v)$ was determined by the slope of the catalytic kinetic curve at the starting point with the extinction coefficient of $5.9 \times$
$10^{4} \mathrm{M}^{-1} \mathrm{~cm}^{-1}$ for oxidized TMB [38]. A plot of $v$ versus TMB or $\mathrm{H}_{2} \mathrm{O}_{2}$ concentrations displays a positive relationship (Fig. 5, a and b), and the corresponding reciprocal plots form straight lines with clear linear relationships (Fig. 5, c and d), which are utilized to calculate the equilibrium catalytic constant $\left(k_{\text {cat }}\right)$. As shown in ESM Table S1, Pd-Ir nanocubes synthesized here display $k_{\text {cat }}$ values of $2.91 \times 10^{6} \mathrm{~S}^{-1}$ and $2.55 \times 10^{6} \mathrm{~S}^{-1}$ for TMB and
Fig. 6 Linear relationships between UV-Vis absorbance of oxidized TMB at $450 \mathrm{~nm}$ and $\mathrm{NP}$ concentrations tested by a HRPbased and $\mathbf{b}$ Pd-Ir nanocubebased immunoassays. Linear relationships between UV-Vis absorbance of oxidized TMB at $450 \mathrm{~nm}$ and PSA concentrations tested by $\mathbf{c}$ HRP- and $\mathbf{d}$ Pd-Ir nanocube-based immunoassays
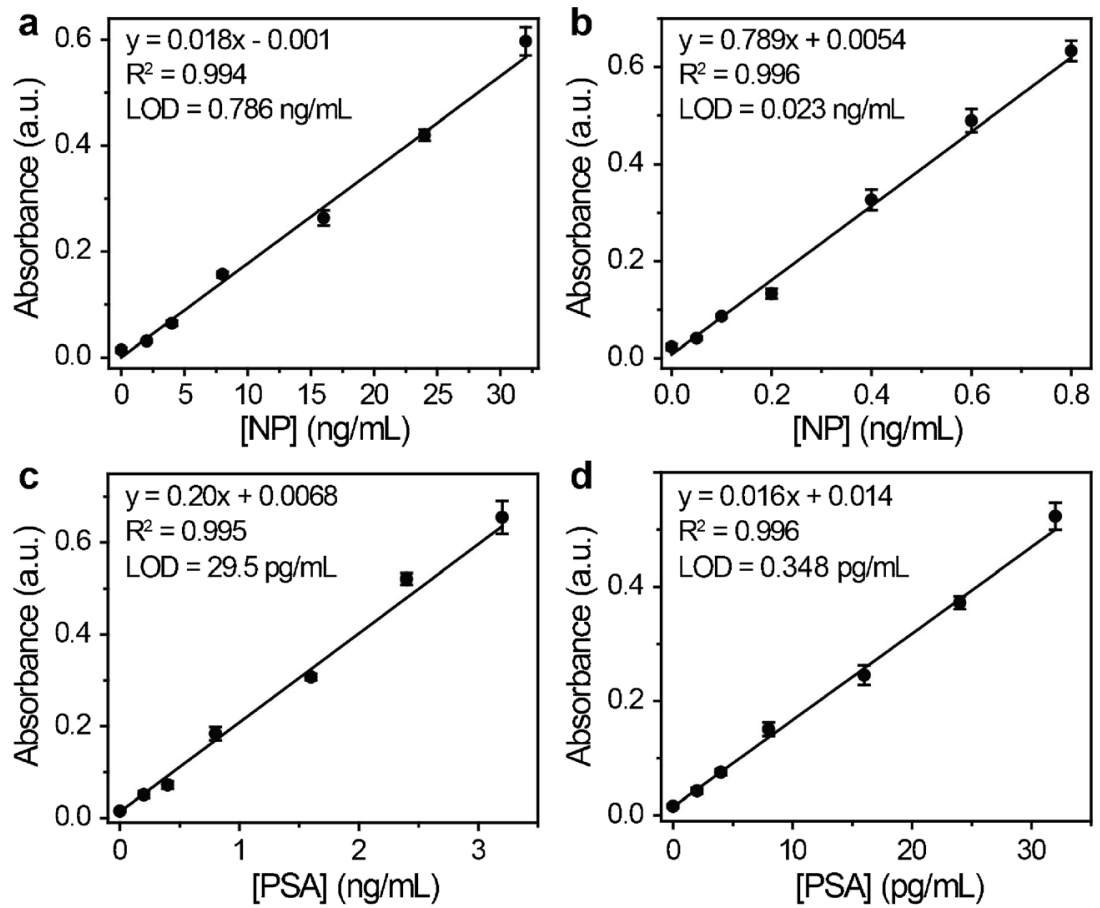
$\mathrm{H}_{2} \mathrm{O}_{2}$, respectively, which are comparable to that of previously described Pd-Ir nanocubes [7] and approximately three orders of magnitude that of HRP. Therefore, this method is promising to expand the application of Pd-Ir nanocube-based immunoassay due to its simple and high-yield synthesis.

\section{Immunoassay of NP and PSA by Pd-Ir nanocubes}

NP is the most abundant structural protein of SARS-CoV2 involved in the incorporation, package, replication, and transcription of viral RNA, and are encoded within a relatively conserved and stable gene, which make NP an ideal candidate for the development of antigen-based immunoassays for the diagnosis of COVID-19 [39-41]. Hence, Pd-Ir nanocubes were conjugated with antibodies to investigate the detection sensitivity for NP of SARSCoV-2 compared with standard HRP-based immunoassay. As shown in Fig. 6, a and b, plots of absorbance at $450 \mathrm{~nm}$ versus the concentrations of NP display linear relationships for both HRP- and Pd-Ir nanocube-based immunoassays, with detection limits of $0.786 \mathrm{ng} / \mathrm{mL}$ and $0.023 \mathrm{ng} / \mathrm{mL}$, respectively. It reveals that Pd-Ir nanocubebased immunoassays are 34 times sensitive than standard HRP-based immunoassays. Furthermore, Pd-Ir nanocubebased method was employed for the detection of NP in saliva. As shown in ESM Fig. S8, signal response increased linearly with the concentration NP with a detection limit of $0.049 \mathrm{ng} / \mathrm{mL}$.

We also employed these two methods for the detection of prostate-specific antigen (PSA) to further confirm the advantages of Pd-Ir nanocube-based immunoassays. Human PSA is a serine protease used for liquefying the seminal fluid and has been deemed as a specific blood biomarker for the diagnosis of prostate cancer and monitoring the effect of treatment [42, 43]. As shown in Fig. 6, c and d, PSA was successfully detected by both HRP- and Pd-Ir nanocube-based immunoassays with detection limits of $29.5 \mathrm{pg} / \mathrm{mL}$ and $0.348 \mathrm{pg} / \mathrm{mL}$, respectively. The results demonstrate that the detection sensitivity for PSA has been enhanced 84-fold by Pd-Ir nanocubebased immunoassay, compared to standard HRP-based immunoassay. Taken together, Pd-Ir nanocube-based immunoassays are promising for clinical diagnostics ascribed to its excellent detection sensitivity.

\section{Conclusions}

A simple and facile method is reported here to synthesize Pd nanocubes for Pd-Ir nanocube-based immunoassay. The yield and reproducibility of Pd nanocubes have been remarkably improved due to the homogenous nucleation afforded by the one-pot synthesis method. Pd nanocubes with sizes ranging from 7 to $51 \mathrm{~nm}$ are readily obtained. Thin Ir layers can be easily coated on the surface of Pd nanocubes with welldefined surface structures, achieving Pd-Ir nanocubes with good synthesis reproducibility and testing performance. Peroxidase activity of Pd-Ir nanocubes described in this research is about three orders of magnitude greater than HRP, providing 34-fold and 84-fold increases in detection sensitivity for NP and PSA, respectively. With excellent features of Pd-Ir nanocubes, such as high activity, good stability, and ease of modification, we hope to further popularize Pd-Ir nanocubes as powerful tools for use in high sensitivity immunoassays.

Supplementary Information The online version contains supplementary material available at https://doi.org/10.1007/s00216-021-03265-z.

Acknowledgements The electron microscopy work was carried out at the Canadian Centre for Electron microscopy supported by CFI, NSERC, and McMaster University. Special appreciation goes to Jimmy Gu for commenting on the manuscript.

Funding This work was supported by funding from Natural Sciences and Engineering Research Council of Canada (NSERC) via a Discovery Grant to YL.

\section{Declarations}

Conflict of interest The authors declare no conflict of interest.

\section{References}

1. Gan SD, Patel KR. Enzyme immunoassay and enzyme-linked immunosorbent assay. J Invest Dermatol 2013;133(9):e12.

2. Wick MR. Histochemistry as a tool in morphological analysis: a historical review. Ann Diagn Pathol. 2012;16(1):71-8.

3. Cheng CM, Martinez AW, Gong J, Mace CR, Phillips ST, Carrilho E, et al. Paper-based ELISA. Angew Chem Int Ed. 2010;49(28): 4771-4.

4. Ramachandran S, Fu E, Lutz B, Yager P. Long-term dry storage of an enzyme-based reagent system for ELISA in point-of-care devices. Analyst. 2014;139(6):1456-62.

5. Murdock RC, Shen L, Griffin DK, Kelley-Loughnane N, Papautsky I, Hagen JA. Optimization of a paper-based ELISA for a human performance biomarker. Anal Chem. 2013;85(23):11634-42.

6. He W, Liu Y, Yuan J, Yin J-J, Wu X, Hu X, et al. Au@ Pt nanostructures as oxidase and peroxidase mimetics for use in immunoassays. Biomaterials. 2011;32(4):1139-47.

7. Xia X, Zhang J, Lu N, Kim MJ, Ghale K, Xu Y, et al. Pd-Ir coreshell nanocubes: a type of highly efficient and versatile peroxidase mimic. ACS Nano. 2015;9(10):9994-10004.

8. Wei H, Wang E. Nanomaterials with enzyme-like characteristics (nanozymes): next-generation artificial enzymes. Chem Soc Rev. 2013;42(14):6060-93.

9. Lin Y, Ren J, Qu X. Catalytically active nanomaterials: a promising candidate for artificial enzymes. Acc Chem Res. 2014;47(4):1097-105.

10. Wu J, Wang X, Wang Q, Lou Z, Li S, Zhu Y, et al. Nanomaterials with enzyme-like characteristics (nanozymes): next-generation artificial enzymes (II). Chem Soc Rev. 2019;48(4):1004-76. 
11. Gao L, Zhuang J, Nie L, Zhang J, Zhang Y, Gu N, et al. Intrinsic peroxidase-like activity of ferromagnetic nanoparticles. Nat Nanotechnol. 2007;2(9):577-83.

12. Wei $\mathrm{H}$, Wang $\mathrm{E} . \mathrm{Fe}_{3} \mathrm{O}_{4}$ magnetic nanoparticles as peroxidase mimetics and their applications in $\mathrm{H}_{2} \mathrm{O}_{2}$ and glucose detection. Anal Chem. 2008;80(6):2250-4.

13. $\mathrm{Mu}$ J, Wang $\mathrm{Y}$, Zhao M, Zhang L. Intrinsic peroxidase-like activity and catalase-like activity of $\mathrm{Co}_{3} \mathrm{O}_{4}$ nanoparticles. Chem Commun. 2012;48(19):2540-2.

14. André R, Natálio F, Humanes M, Leppin J, Heinze K, Wever R, et al. $\mathrm{V}_{2} \mathrm{O}_{5}$ nanowires with an intrinsic peroxidase-like activity. Adv Funct Mater. 2011;21(3):501-9.

15. Chen W, Chen J, Liu AL, Wang LM, Li GW, Lin XH. Peroxidaselike activity of cupric oxide nanoparticle. ChemCatChem. 2011;3(7):1151-4.

16. Song Y, Wang X, Zhao C, Qu K, Ren J, Qu X. Label-free colorimetric detection of single nucleotide polymorphism by using single-walled carbon nanotube intrinsic peroxidase-like activity. Chem Eur J. 2010;16(12):3617-21.

17. Song Y, Qu K, Zhao C, Ren J, Qu X. Graphene oxide: intrinsic peroxidase catalytic activity and its application to glucose detection. Adv Mater. 2010;22(19):2206-10.

18. He W, Wu X, Liu J, Hu X, Zhang K, Hou S, et al. Design of AgM bimetallic alloy nanostructures $(\mathrm{M}=\mathrm{Au}, \mathrm{Pd}, \mathrm{Pt})$ with tunable morphology and peroxidase-like activity. Chem Mater. 2010;22(9):2988-94.

19. JV Y, Li B, Cao R. Positively-charged gold nanoparticles as peroxidiase mimic and their application in hydrogen peroxide and glucose detection. Chem Commun. 2010;46(42):8017-9.

20. Xia X, Figueroa-Cosme L, Tao J, Peng H-C, Niu G, Zhu Y, et al. Facile synthesis of iridium nanocrystals with well-controlled facets using seed-mediated growth. J Am Chem Soc. 2014;136(31):10878-81.

21. Tao X, Wang X, Liu B, Liu J. Conjugation of antibodies and aptamers on nanozymes for developing biosensors. Biosens Bioelectron. 2020. https://doi.org/10.1016/j.bios.2020.112537.

22. Zanata CR, Martins CA, Teixeira-Neto E, Giz MJ, Camara GA. Two-step synthesis of Ir-decorated Pd nanocubes and their impact on the glycerol electrooxidation. J Catal. 2019;377:358-66.

23. Zhu J, Lyu Z, Chen Z, Xie M, Chi M, Jin W, et al. Facile synthesis and characterization of $\mathrm{Pd} @ \mathrm{Ir}_{\mathrm{nL}}(\mathrm{n}=1-4)$ core-shell nanocubes for highly efficient oxygen evolution in acidic media. Chem Mater. 2019;31(15):5867-75.

24. Zhu N, Zhang D, Wang W, Li X, Yang B, Song J, et al. A novel coronavirus from patients with pneumonia in China, 2019. N Engl J Med. 2020;382(8):727-33.

25. Wu F, Zhao S, Yu B, Chen Y-M, Wang W, Song Z-G, et al. A new coronavirus associated with human respiratory disease in China. Nature. 2020;579(7798):265-9.

26. Chan JF-W, Yuan S, Kok K-H, To KK-W, Chu H, Yang J, et al. A familial cluster of pneumonia associated with the 2019 novel coronavirus indicating person-to-person transmission: a study of a family cluster. Lancet. 2020;395(10223):514-23.

27. Wang W, Xu Y, Gao R, Lu R, Han K, Wu G, et al. Detection of SARS-CoV-2 in different types of clinical specimens. Jama. 2020;323(18):1843-4.

28. Li Z, Yi Y, Luo X, Xiong N, Liu Y, Li S, et al. Development and clinical application of a rapid IgM-IgG combined antibody test for SARS-CoV-2 infection diagnosis. J Med Virol. 2020;92(9):1518-24.
29. Udugama B, Kadhiresan P, Kozlowski HN, Malekjahani A, Osborne M, Li VY, et al. Diagnosing COVID-19: the disease and tools for detection. ACS Nano. 2020;14(4):3822-35.

30. Liu W, Liu L, Kou G, Zheng Y, Ding Y, Ni W, et al. Evaluation of nucleocapsid and spike protein-based enzyme-linked immunosorbent assays for detecting antibodies against SARS-CoV-2. J Clin Microbiol. 2020;58(6):e00461-20.

31. Broughton JP, Deng X, Yu G, Fasching CL, Servellita V, Singh J, et al. CRISPR-Cas12-based detection of SARS-CoV-2. Nat Biotechnol. 2020;38(7):870-4

32. Tahamtan A, Ardebili A. Real-time RT-PCR in COVID-19 detection: issues affecting the results. Expert Rev Mol Diagn. 2020;20(5):453-4.

33. Zhang L, Fang X, Liu X, Ou H, Zhang H, Wang J, et al. Discovery of sandwich type COVID-19 nucleocapsid protein DNA aptamers. Chem Commun. 2020;56(70):10235-8.

34. Chen Z, Wu Q, Chen J, Ni X, Dai J. A DNA aptamer based method for detection of SARS-CoV-2 nucleocapsid protein. Virol Sin. 2020;35(3):351-4.

35. Grant BD, Anderson CE, Williford JR, Alonzo LF, Glukhova VA, Boyle DS, et al. SARS-CoV-2 coronavirus nucleocapsid antigendetecting half-strip lateral flow assay toward the development of point of care tests using commercially available reagents. Anal Chem. 2020;92(16):11305-9.

36. Diao B, Wen K, Zhang J, Chen J, Han C, Chen Y, et al. Accuracy of a nucleocapsid protein antigen rapid test in the diagnosis of SARSCoV-2 infection. Clin Microbiol Infect. 2020. https://doi.org/10. 1016/j.cmi.2020.09.057.

37. Lim B, Jiang M, Tao J, Camargo PHC, Zhu Y, Xia Y. Shapecontrolled synthesis of Pd nanocrystals in aqueous solutions. Adv Funct Mater. 2009;19(2):189-200.

38. Josephy PD, Eling T, Mason RP. The horseradish peroxidasecatalyzed oxidation of 3, 5, 3', 5'-tetramethylbenzidine. Free radical and charge-transfer complex intermediates. J Biol Chem. 1982;257(7):3669-75.

39. Kang S, Yang M, Hong Z, Zhang L, Huang Z, Chen X, et al. Crystal structure of SARS-CoV-2 nucleocapsid protein RNA binding domain reveals potential unique drug targeting sites. Acta Pharm Sin B. 2020;10(7):1228-38.

40. Hodge CD, Rosenberg DJ, Wilamowski M, Joachimiak A, Hura GL, Hammel M. Rigid monoclonal antibodies improve detection of SARS-CoV-2 nucleocapsid protein. bioRxiv. 2021. https://doi.org/ 10.1101/2021.01.13.426597.

41. Ye Q, West AM, Silletti S, Corbett KD. Architecture and selfassembly of the SARS-CoV-2 nucleocapsid protein. Protein Sci. 2020;29(9):1890-901.

42. Lilja H, Ulmert D, Vickers AJ. Prostate-specific antigen and prostate cancer: prediction, detection and monitoring. Nat Rev Cancer. 2008;8(4):268-78.

43. Wu G, Datar RH, Hansen KM, Thundat T, Cote RJ, Majumdar A. Bioassay of prostate-specific antigen (PSA) using microcantilevers. Nat Biotechnol. 2001;19(9):856-60.

Publisher's note Springer Nature remains neutral with regard to jurisdictional claims in published maps and institutional affiliations. 


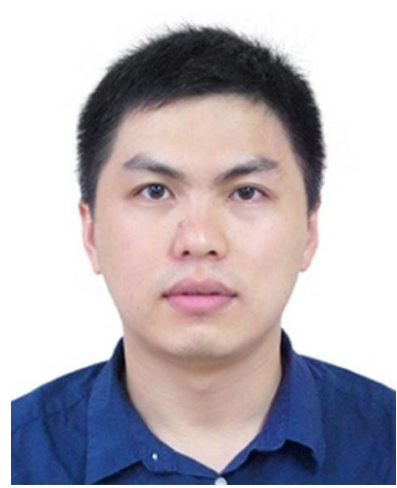

Jiuxing $\mathbf{L i}$ is a postdoctoral fellow at McMaster University under the supervision of Prof. Yingfu Li. He has been working on the development of functional nucleic acidbased diagnostics.

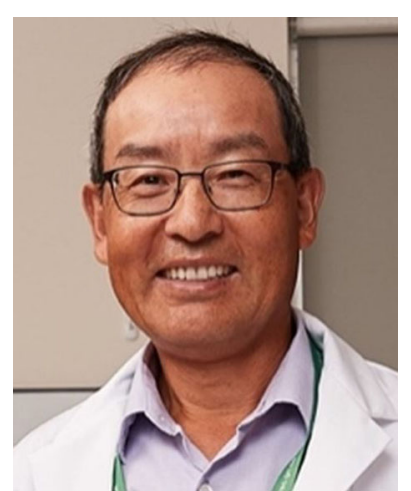

Yingfu Li is Full Professor in the Department of Biochemistry and Biomedical Sciences at McMaster University. His group studies DNAzymes, aptamers, biosensors, nanotechnology, and noncoding RNA. 